\title{
NATIONAL TIME TRENDS IN BULLYING AMONG ADOLESCENTS IN THE CZECH REPUBLIC FROM 1994 TO 2014
}

\author{
Mária Sarková1, Dagmar Sigmundová2, Michal Kalman² \\ ${ }^{1}$ Department of Recreation and Leisure Studies, Faculty of Physical Culture, Palacký University Olomouc, Olomouc, Czech Republic \\ ${ }^{2}$ Institute of Active Lifestyle, Faculty of Physical Culture, Palacký University Olomouc, Olomouc, Czech Republic
}

\section{SUMMARY}

Objective: Bullying in school is a public health concern which continues to be a serious threat to physical and emotional health of children and adolescents. The purpose of this study is to examine trends in bullying behaviour among school-aged children in the Czech Republic.

Methods: Data were obtained from cross-sectional self-report surveys in the years 1994-2014 as a part of the Health Behaviour in School-aged Children study (HBSC) from a representative sample of 11-, 13-, and 15-year olds.

Results: The highest proportion of children who bullied others (20-47\%) occurred during the years 1994 and 1998. The logistic regression models showed significant decreasing trends in bullying others and also in being bullied, regardless of age and gender.

Conclusion: The decreasing trend in bullying may be the consequence of a preventive policy in the Czech Republic, but also a change in the understanding of the concept of bullying in society.

Key words: bullying, HBSC, trend, behaviour, risk

Address for correspondence: M. Sarková, Department of Recreation and Leisure Studies, Faculty of Physical Culture, Palacký University Olomouc, trída Míru 111, 77111 Olomouc, Czech Republic. E-mail: marika.sarkova@gmail.com

https://doi.org/10.21101/cejph.a5098

\section{INTRODUCTION}

Bullying in adolescence has been recognized as a serious problem in recent years and a worrying issue concerning its impact on youths health and psychosocial adjustment (1-3). This type of behaviour has been defined as a form of intentional harmful behaviour, carried out repeatedly, in which, without being provoked, a student or students physically or verbally assault another student who is unable to defend him/herself (4). Previous studies have shown that bullying behaviour has a detrimental effect on both victims and offenders (2). It was associated with negative outcomes such as psychological maladjustment (psychological well-being, self-esteem, and self-confidence) $(3,5-8)$, psychosomatic health problems (9), and involvement in substance use and other risk behaviours (10-13).

Bullying behaviour and its changes over time have been monitored repeatedly across countries. The study by Chester et al. (14) showed significant decreasing trends in occasional and chronic victimization between 2001/02 and 2009/10 across both genders in a third of the participating countries. On the contrary, Belgium and Finland reported significant increasing trends for both occasional and chronic victimization. In spite of the reported overall decrease in European adolescents bullying others, more detailed monitoring of the prevalence amongst Czech children and adolescents could be used to provide critical information in the arising forms of cyberbullying.
Therefore, this study assessed the trends in the prevalence of bullying of school-aged children in the Czech Republic from 1994 to 2014.

\section{MATERIALS AND METHODS}

\section{Sample and Procedure}

This research is a part of the international WHO collaborative study Health Behaviour in School-aged Children study (HBSC). HBSC is a cross-national research study monitoring various health and lifestyle determinants in school-aged children. School-based anonymous surveys were conducted in the academic years ending of 1994, 1998, 2002, 2006, 2010, and 2014 according to a common research protocol (15-20). A national representative sample of children aged 11,13 , and 15 years was selected in these years. The completion of the HBSC questionnaire by children was voluntary. The final data inspection was performed by the International Databank, University of Bergen, Norway, in compliance with the international HBSC standards. The 1994 data included 1,693 children (47.4\% of boys), in 1998 data included 3,020 (49.1\% of boys), and in 20024,044 children ( $47.3 \%$ of boys); in 2006 data included 4,118 children ( $50.66 \%$ of boys), in 20103,847 children ( $47.5 \%$ of boys), and the latest data collection in 2014 included 4,357 children ( $48.7 \%$ of boys) eligible for the analysis. 


\section{Measures}

\section{Bullying}

Bullying behaviour was measured by the following two items: "During this term, how often have you been bullied at school in the past couple of months?" and "During this term, how often have you bullied others at school in the past couple of months?" (20-22). The response categories for both items were: never, once or twice, 2-3 times per month, once a week, several times a week. The responses were re-coded into two levels: never and at least once or twice or more.

\section{Statistical Analysis}

Statistical analysis was conducted in the IBM SPSS 22 software for Windows. For the trend, a logistic regression analysis (Enter method) was used with a dependent variable - who bullied someone at least once or more and who were bullied at least once or more - and an independent categorical variable, which was the year that the survey was completed (1994, 1998, 2002, 2006, 2010, 2014), with 1994 as the reference year.

\section{RESULTS}

Table 1 presents the prevalence rates of children who bullied others, split by gender and age. During the period from 1994 to 1998 , we observed the highest proportion of children who bullied others (20-47\%). Nevertheless, in the following period (2002-2014) this proportion decreased considerably compared to 1994-1998. Boys and girls in all age categories in 2014 were less likely to bully others than in 1994. Between 2002 and 2010 there were no significant changes in the prevalence of bullying others (regardless of age and gender).

In 2014, 11-year-old boys were more likely to bully others $(\mathrm{OR}=1.46 ; \mathrm{p}<0.05)$ compared with 2002 (the year 2002 was reference group). This increase is evident after 2006 (reference group) in comparison with $2014\left(\mathrm{OR}_{2014 \text { vs. } 2006}=1.51 ; \mathrm{p}<0.01\right)$ and also between 2010 (reference group) and $2014\left(\mathrm{OR}_{2014}\right.$ vs. 2010 $=1.75 ; \mathrm{p}<0.01)$.
On the other hand, a significant decrease in the odds of bullying others was shown in 15 -year-old boys $\left(\mathrm{OR}_{2014 \text { vs. } 2002}=\right.$ $0.71 ; \mathrm{p}<0.01)$, girls $\left(\mathrm{OR}_{2014 \text { vs. } 2002}=0.74 ; \mathrm{p}<0.05\right)$ and also in 13 -year-old girls $\left(\mathrm{OR}_{2014 \text { vs. } 2002}=0.69 ; \mathrm{p}<0.05\right)$ (the year 2002 was reference group).

The children in 2014 perceived that they were significantly less likely to be bullied (Table 2) than the children in 1994 (both boys and girls in all age categories). A decrease in bullying is evident until the year 2002. After 2002, we found a significant increase in bullying in 13-year-old girls between 2002 (reference group) and $2014\left(\mathrm{OR}_{2014 \text { vs. } 2002}=1.45 ; \mathrm{p}<0.01\right)$ and also between 2010 (reference group) and $2014\left(\mathrm{OR}_{2014 \text { vs. } 2010}=1.32 ; \mathrm{p}<0.05\right)$. In the other categories, there were no significant changes among the years 2002, 2006, 2010, and 2014.

\section{DISCUSSION}

The present study assessed the trends in the prevalence of bullying of school-aged children and adolescents in the Czech Republic from 1994 to 2014. As indicated by our results, during the period 1994-1998, we observed the highest proportion of children who bullied others. Nevertheless, in the following period (2002-2014) this proportion decreased considerably compared to 1994 and 1998 and no significant changes were found between 2002 and 2010 in the prevalence of bullying others (regardless of age and gender). Children in 2014 perceived that they were significantly less likely to be bullied than children in 1994 (both boys and girls in all age categories). A decrease in bullying is evident until the year 2002 .

Our results are in line with cross-national comparisons presented for bullying and also for fighting $(14,24)$. In contrast with the study of Chester et al. (14), the methodology of our study covers a wider period of the two decades from 1994 to 2014. The most significant change in the prevalence of bullying is evident between 1998 and 2002. In all age groups and among both, boys and girls, decrease in bullying was observed. There are several possible explanations for this change, beginning with the political transformation which created a climate of change that is evident on the school level. Various forms of risk behaviour among

Table 1. Trends in the prevalence of bullying others: HBSC study, 1994 to 2014

\begin{tabular}{|c|c|c|c|c|c|c|c|c|c|}
\hline \multirow{3}{*}{ Variable } & 1994 & 1998 & 2002 & 2006 & 2010 & 2014 & & 14 vs. 19 & \\
\hline & \multirow{2}{*}{$\%$} & \multirow{2}{*}{$\%$} & \multirow{2}{*}{$\%$} & \multirow{2}{*}{$\%$} & \multirow{2}{*}{$\%$} & \multirow{2}{*}{$\%$} & \multirow{2}{*}{ OR } & \multicolumn{2}{|c|}{$\mathrm{Cl}$} \\
\hline & & & & & & & & Lower & Upper \\
\hline \multicolumn{10}{|l|}{ Boys } \\
\hline $11-11.99$ years & 46.5 & 33.7 & 12.1 & 11.7 & 10.3 & 16.7 & $0.23^{* * *}$ & 0.17 & 0.32 \\
\hline $13-13.99$ years & 42.5 & 34.2 & 21.3 & 19.2 & 17.3 & 20.5 & $0.35^{* * *}$ & 0.26 & 0.47 \\
\hline $15-15.99$ years & 38.9 & 46.4 & 25.7 & 23.2 & 23.2 & 19.8 & $0.39^{\star \star *}$ & 0.29 & 0.52 \\
\hline \multicolumn{10}{|l|}{ Girls } \\
\hline $11-11.99$ years & 37.5 & 23.2 & 7.6 & 7.6 & 8.1 & 8.3 & $0.15^{\star \star *}$ & 0.10 & 0.22 \\
\hline $13-13.99$ years & 33.2 & 27.6 & 15.0 & 13.6 & 11.8 & 10.9 & $0.25^{\star \star \star}$ & 0.18 & 0.34 \\
\hline $15-15.99$ years & 20.7 & 28.4 & 14.7 & 13.7 & 12.6 & 11.3 & $0.49^{* * *}$ & 0.34 & 0.70 \\
\hline
\end{tabular}

Results from logistic regression; \% percentage of participants who bullied others at least once or more; OR: odds ratio (cohorts from the year 1994 are reference groups); Cl: $95 \%$ confidence interval; ${ }^{*} p \leq 0.05 ;{ }^{* *} p \leq 0.01 ;{ }^{* * *} p \leq 0.001$ 
Table 2. Trends in the prevalence of children who were bullied: HBSC study, 1994 to 2014

\begin{tabular}{|c|c|c|c|c|c|c|c|c|c|}
\hline & 1994 & 1998 & 2002 & 2006 & 2010 & 2014 & \multicolumn{3}{|c|}{2014 vs. 1994} \\
\hline & \multirow{2}{*}{$\%$} & \multirow{2}{*}{$\%$} & \multirow{2}{*}{$\%$} & \multirow{2}{*}{$\%$} & \multirow{2}{*}{$\%$} & \multirow{2}{*}{$\%$} & \multirow{2}{*}{ OR } & \multicolumn{2}{|c|}{$\mathrm{Cl}$} \\
\hline & & & & & & & & Lower & Upper \\
\hline \multicolumn{10}{|l|}{ Boys } \\
\hline $11-11.99$ years & 57.9 & 35.2 & 17.5 & 19.5 & 16.6 & 20.2 & $0.18^{* * *}$ & 0.13 & 0.25 \\
\hline $13-13.99$ years & 41.8 & 40.4 & 20.3 & 18.0 & 17.0 & 19.7 & $0.34^{* * *}$ & 0.25 & 0.46 \\
\hline $15-15.99$ years & 29.9 & 42.0 & 14.2 & 12.4 & 15.8 & 14.7 & $0.41^{* * *}$ & 0.29 & 0.56 \\
\hline \multicolumn{10}{|l|}{ Girls } \\
\hline $11-11.99$ years & 49.3 & 34.1 & 14.6 & 14.1 & 14.7 & 17.3 & $0.22^{* \star *}$ & 0.16 & 0.29 \\
\hline $13-13.99$ years & 37.8 & 33.2 & 14.3 & 16.9 & 15.5 & 19.6 & $0.40^{* * *}$ & 0.30 & 0.53 \\
\hline $15-15.99$ years & 22.4 & 34.8 & 13.7 & 15.1 & 14.8 & 15.1 & $0.61^{* *}$ & 0.44 & 0.86 \\
\hline
\end{tabular}

Results from logistic regression; \% percentage of participants who were bullied at least once or more; OR: odds ratio (cohorts from the year 1994 are reference groups); Cl: $95 \%$ confidence interval; ${ }^{*} p \leq 0.05 ;{ }^{* *} p \leq 0.01 ;{ }^{* *} p \leq 0.001$

school-aged children started to be monitored, explored, and dealt with on the regional and national level as a part of school-based intervention programmes. During that time open dialogue and the establishment of national organizations protecting victims started simultaneously, resulting in greater sensitivity towards this topic (25).

This study was based on a large national representative dataset which allows for unique examinations of temporal trends in bullying behaviour; however, there are some limitations to this study. First, the observed data was self-reported, and the children's responses about their experience of bullying are subjective. In addition to that, all the participating countries have to use the same HBSC protocol, using the same definition and wording of the question about bullying behaviour. However, the term 'bullying' often cannot be readily translated into other languages and could be understood differently across cultures (26). Finally, in the past decade cyberbullying, bullying through electronic devices and social networks, has been recognized as another form of bullying $(3,27,28)$. For example, as found out in the study by Ševčíková and Šmahel (28), the highest proportion of aggressors was among younger (12-15 years) and older (16-19 years) Czech adolescents. It must be noted that the measure used in the HBSC surveys did not explicitly refer to cyberbullying; consequently, the prevalence rates may reflect only traditional forms of bullying and not cyberbullying (14).

In summary, we observed a significant decrease in behaviours, bullying others and also being bullied, in all age categories and both genders. This positive trend may be the result of a preventive policy in the Czech Republic, but also a change in the understanding of the concept of bullying in society.

The identification of trend in bullying should be considered as a guideline for the development of effective anti-bullying programmes. Several programmes have been implemented across Europe on national and regional level. There are anti-bullying programmes in the Czech Republic focused on individuals, peer groups and school environment levels. All age groups and all types of this behaviour are being covered in these programmes. Online links and helplines for crisis intervention are additional form of help. It should be kept in mind that all prevention should be updated based on current situation.

\section{Acknowledgement}

This work was supported by the research grant of the Czech Science Foundation Reg. No. 17-12579S and by the Czech Ministry of Education, Youth, and Sports (MEYS) under Contract No. LG 14043.

\section{Conflict of Interests}

None declared

\section{REFERENCES}

1. Roland E, Galloway D. Classroom influences on bullying. Educ Res. 2002;44(3):299-312.

2. Ma X. Bullying in middle school: individual and school characteristics of victims and offenders. Sch Eff Sch Improv. 2002 Mar;13(1):63-89.

3. Callaghan M, Kelly C, Molcho M. Exploring traditional and cyberbullying among Irish adolescents. Int J Public Health. 2015 Feb;60(2):199-206.

4. Olweus D. Bullying at school: what we know and what we can do. Malden (MA): Blackwell Publishing; 1993.

5. Harel-Fisch Y, Walsh SD, Fogel-Grinvald H, Amitai G, Pickett W, Molcho M, et al.; Members of the HBSC Violence and Injury Prevention Focus Group. Negative school perceptions and involvement in school bullying: a universal relationship across 40 countries. J Adolesc. 2011 Aug;34(4):639-52.

6. Sarkova M, Bacikova-Sleskova M, Madarasova Geckova A, Katreniakova Z, van den Heuvel W, van Dijk JP. Adolescents' psychological well-being and self-esteem in the context of relationships at school. Educ Res. 2014;56(4):367-78

7. O'Moore M, Kirkham C. Self-esteem and its relationship to bullying behaviour. Aggress Behav. $2001 \mathrm{Jul} ; 27(4): 269-83$.

8. Hawker DS, Boulton MJ. Twenty years' research on peer victimization and psychosocial maladjustment: a meta-analytic review of cross-sectional studies. J Child Psychol Psychiatry. 2000 May;41(4):441-55.

9. Nansel TR, Overpeck M, Pilla RS, Ruan WJ, Simons-Morton B, Scheidt P. Bullying behaviors among US youth: prevalence and association with psychosocial adjustment. JAMA. 2001 Apr 25;285(16):2094-100.

10. Hemphill SA, Kotevski A, Heerde JA. Longitudinal associations between cyber-bullying perpetration and victimization and problem behavior and mental health problems in young Australians. Int J Public Health. 2015 Feb;60(2):227-37.

11. Sinclair KO, Bauman S, Poteat VP, Koenig B, Russell ST. Cyber and bias-based harassment: associations with academic, substance use, and mental health problems. J Adolesc Health. 2012 May;50(5):521-3.

12. Smokowski PR, Kopasz KH. Bullying in school: an overview of types, effects, family characteristics, and intervention strategies. Child Sch. 2005 Apr;27(2):101-10.

13. Vieno A, Gini G, Santinello M. Different forms of bullying and their association to smoking and drinking behavior in Italian adolescents. J Sch Health. 2011 Jul;81(7):393-9. 
14. Chester KL, Callaghan M, Cosma A, Donnelly P, Craig W, Walsh S, et al. Cross-national time trends in bullying victimization in 33 countries among children aged 11, 13 and 15 from 2002 to 2010. Eur J Public Health. 2015 Apr;25 Suppl 2:61-4.

15. Currie C, Griebler R, Inchley J, Theunissen A, Molcho M, Samdal O, et al., editors. Health Behaviour in School-Aged Children (HBSC) study protocol: background, methodology and mandatory items for the 2009/10 survey. Edinburgh: Health Behaviour in School-Aged Children (HBSC); 2010.

16. Currie C, Inchley J, Molcho M, Lenzi M, Veselska Z, Wild F, editors. Health Behaviour in School-aged Children (HBSC) study protocol: background, methodology and mandatory items for the 2013/2014 survey [Internet]. St Andrews: HBSC International Coordinating Centre; 2014 [cited 2017 Jul 10]. Available from: https://www.hbsc.org.

17. Currie C, Samdal O, Boyce W, Smith R, editors. Health behaviour in school-aged children: A WHO cross-national study (HBSC), research protocol for the 2001/2002 survey. Edinburgh: CAHRU; 2001.

18. Interntional HBSC study group. HBSC research protocol for $2005 / 06$ survey. Section 2. Scientific rationales for focus areas [unpublished paper]. 2005.

19. Wold B, Smith C, Aarø LE. Health behaviour in school-aged children, A WHO cross-national survey (HBSC): research protocol for the 199394 study: Research Center for Health Promotion. Bergen: University of Bergen; 1994.

20. Currie C. Health behaviour in school-aged children. A WHO crossnational survey (HBSC): research protocol for the 1997-1998 study. Edinburgh: University of Edinburgh; 1998.

21. Olweus D. Prevalence and incidence in the study of antisocial behavior: definitions and measurements. In: Klein MW, editor. Cross-national research in self-reported crime and delinquency. NATO ASI Series (Series
D: Behavioural and Sciences), vol. 50. Dordrecht: Springer; 1989. p. 187-201.

22. Olweus D. The revised Olweus bully/victim questionnaire. Bergen University of Bergen, Research Center for Health Promotion; 1996.

23. Inchley J, Currie D, Young T, Samdal O, Torsheim T, Augustson L, et al., editors. Growing up unequal: gender and socioeconomic differences in young people's health and well-being. Health Behaviour in School-aged Children (HBSC) study: international report from the 2013/2014 survey. Copenhagen: WHO Regional Office for Europe; 2016.

24. Pickett W, Molcho M, Elgar FJ, Brooks F, de Looze M, Rathmann K, et al. Trends and socioeconomic correlates of adolescent physical fighting in 30 countries. Pediatrics. 2013 Jan;131(1):e18-26.

25. Kolář M. Specific programme against bullying and violence at school. Prague: Ministry of Education, Youth and Sports of the Czech Republic; 2003. (In Czech.)

26. Craig WM, Henderson K, Murphy JG. Prospective teachers' attitudes toward bullying and victimization. Sch Psychol Int. 2000 Feb;21(1):5-21.

27. Spears BA, Taddeo CM, Daly AL, Stretton A, Karklins LT. Cyberbullying, help-seeking and mental health in young Australians: implications for public health. Int J Public Health. 2015 Feb;60(2):219-26.

28. Ševčíková A, Šmahel D. Online harassment and cyberbullying in the Czech Republic: comparison across age groups. Z Psychol. 2009;217(4):227-9.

Received March 9, 2017 Accepted in revised form July 10, 2017 